\title{
How to manage biocomposites wastes end of life? A life cycle assessment approach (LCA) focused on polypropylene (PP)/wood flour and polylactic acid (PLA)/flax fibres biocomposites
}

\author{
Joana Beigbeder ${ }^{\mathrm{a}, *}$, Lata Soccalingame ${ }^{\mathrm{b}}$, Didier Perrin ${ }^{\mathrm{b}}$, Jean-Charles Bénézet ${ }^{\mathrm{b}}$, Anne Bergeret ${ }^{\mathrm{b}}$ \\ ${ }^{a}$ C2MA, Ecole des Mines d'Alès, Hélioparc 2, Avenue P. Angot, 64053 Pau Cedex 9, France \\ ${ }^{\mathrm{b}}$ C2MA, Ecole des Mines d'Alès, 6, Avenue de Clavières, 30319 Alès Cedex France
}

\begin{abstract}
A B S T R A C T
Biocomposites has gained increasing attention in recent years. The environmental impacts of end-of-life (EoL) treatments of those emerging materials should be evaluated before they are produced and installed commercially, to ensure a minimal impact of these products all along their life cycle. Life cycle assessment (LCA) was carried out to evaluate environmental impacts of the EoL treatments of wood flour $(\mathrm{WF})$ reinforced polypropylene (PP/WF) and flax fibers reinforced polylactic acid (PLA/Fl). The aim was to evaluate which EoL was the most environmental friendly to manage those emerging wastes in France and to help stakeholders of the waste sectors in their decisions. The attributional LCA was realized using the methodological framework of the international standard ISO 14040:2006. The study only focuses on the EoL of the biocomposites with four scenarios: incineration, landfill, composting and recycling. Mid-point indicators were evaluated thanks to the Recipe method. Results were also normalized to the annual mean environmental impact of a European inhabitant. For both biocomposites, recycling EoL scenario presents the lowest environmental impacts except for the freshwater eutrophication impact of the PP/WF EoL. Models should be completed in the future when new data will be available. Results obtained for both biocomposites are in agreement with the European waste hierarchy.

If recycling of plastic is difficult to implement, incineration would be the preferable option for the $\mathrm{PP} /$ WF composite, while composting would be the other choice for PLA/Fl material.
\end{abstract}

Keywords:

Life cycle assessment

End-of-life

Biocomposites

Vegetal fillers

Polypropylene

Polylactic acid

\section{Introduction}

Environmental concerns lead researchers and industrials to develop alternatives to fully petro-sourced materials. Therefore, biobased polymers (European Bioplastics, 2013; Shen et al., 2010) and biocomposites have emerged and boomed (Zini and Scandola, 2011) in the world during the ten past years. The term of biocomposites refers here to reinforced polymer composite materials, where the fibers and/or the matrix are bio-based, as for instance natural fibers reinforced composites (NFC) or wood plastic composites (WPC). They are mainly used in the field of automotive, for some parts of the interior, but also in the building sector, for instance for decking. Wood flour, but also flax, sisal, hemp or kenaf fibers are mainly used in biocomposites (Chen and Porter, 1994; Joseph et al., 1996). Compared to conventional glass fibers reinforced composites, it is nowadays well known that

\footnotetext{
* Corresponding author.

E-mail address: joana.beigbeder@mines-ales.fr (J. Beigbeder).
}

biocomposites have better specific mechanical properties (i.e. mechanical properties related to density) (González-Sánchez et al., 2016; Puech et al., 2018; Sarasini and Fiore, 2018), thus they can be considered as challenging alternatives in some applications. Nevertheless if the renewability of the biobased components of biocomposites is an acquired aspect, the management of the biocomposites end of life (EoL) is not always clearly debated.

Different options can be envisaged for biocomposites wastes: recycling, incineration, composting or landfilling. Mechanical recycling of biocomposites, which consists in producing a new material by extrusion after some steps of washing, shredding and sorting, is nowadays studied (Le Duigou et al., 2008; Soccalingame et al., 2015a, 2015b; Srebrenkoska et al., 2008). Most of times, recycling lead to a decrease of the mechanical properties, sometimes due to fibres shortened during processes (Bensadoun et al., 2016; Bhattacharjee and Bajwa, 2018). For PLA-based composites, composting has also been investigated (Bayerl et al., 2014; Othman et al., 2012; Pradhan et al., 2010), the presence of natural biomass improve the degradation of the material. As it's a fast and easy 
technique, incineration with energy recovery is the most widespread technique for composite wastes after landfill (Bensadoun et al., 2016).

Life cycle assessment (LCA) is a method developed to evaluate the environmental impacts of a product or a system (Pennington et al., 2004; Rebitzer et al., 2004). LCA technique presents the advantages to consider the entire life cycle of a product, from 'cradle to grave' or 'cradle to cradle' and to study several environmental impacts all at once. It can also be applied to a process or a life cycle step of a product. It consists in inventorying all the inputs and outputs of the product or system, and then to evaluate each potential environmental impact thanks to specific mathematical models. LCA follows a standardised framework defined in ISO standards (ISO 14040:2006; ISO 14044:2006).

LCA has already been used to determine the environmental impacts of some "green material solutions" compared to petrosourced materials. In most of the studies the environmental benefits of using natural fibers as reinforcements in polymers in replacement of glass fibers were evaluated (Corbière-Nicollier et al., 2001; Dornburg et al., 2003; Joshi et al., 2004; La Rosa et al., 2013; Schmidt and Beyer, 1998). Results commonly showed that natural fibers are more environmental friendly than glass fibers. The production phase is particularly determinant as natural fibers are derived from renewable resources and processes of natural fibres extraction require low energy inputs. The use phase is also important especially in automotive applications as natural fibers reinforced biocomposites are lighter than glass.

Eol steps lead to notable credits thanks to incineration or recycling. For conventional plastics, biocomposites and emerging biodegradable plastics, LCA was also applied to evaluate EoL management (Jenseit et al., 2003; Lazarevic et al., 2010; Rigamonti et al., 2014; Ross and Evans, 2003; Rossi et al., 2015; Shonfield, 2008; Sommerhuber et al., 2017). The main options evaluated to manage plastic wastes are landfill, incineration and recycling. In most of studies, LCA results confirm the waste hierarchy policy established by the European commission, which prioritizes waste reduction, re-use of products, recycling of material, recovery of energy and at last, landfilling (European Commission, 2008). Indeed, the recycling of plastic wastes avoids notable environmental impacts thanks to the production of a secondary raw material, however some key parameters can modify the trend (organic contamination, recycled materials properties) (Lazarevic et al., 2010). However specific data about end of life treatments of biocomposites are missing.

Several approaches exist to model the recycling during a LCA. The most used are the cut-off approach, where only impacts of the recycling steps are considered when using a recycled material, and the avoided burden approach, where impacts of the production of recycled materials are deduced from the studied system (Frischknecht, 2010). This aspect of the modelling of EoL is still debated and a consensus has still not been found (Koffler and Finkbeiner, 2018).

Here, this study focus on the evaluation of the environmental impacts of the different EoL options of two common biocomposites in France: polypropylene reinforced with wood flour (PP/WF) and polylactic acid (PLA), a biodegradable and biobased polymer, reinforced with flax fibres (PLA/Fl). Four options have been considered to model the EoL of the studied composites: landfill, incineration with energy recovery, mechanical recycling and industrial composting for PLA/Fl. Laboratory experiments were carried out to provide some of the life cycle inventory data.

\section{Methodology}

LCA is a standardized method according to ISO 14040/44 series; it's divided in four main steps: goal and definition, inventory analysis, impact assessment and interpretation.
The recent hybrid Recipe method was chosen to evaluate the environmental impacts of the system (Goedkoop et al., 2009), this consensual method is adapted to the European area. Eight midpoint indicators were selected: climate change (CC), ozone depletion (OD), terrestrial acidification (TA), freshwater eutrophication (FE), photochemical oxidation (PO), fossil depletion (FD), human toxicity (HT) and freshwater toxicity (FT). LCA modelling was made with the Thinkstep software Gabi® (Thinkstep, 2015), with the ecoinvent 2.2 version (Ecoinvent Life Cycle Impact assessment database, 2006). To complete the study, indicator results were normalized to the annual mean environmental impact of a European inhabitant (EU-27 year 2000) with the Recipe normalisation factors. This normalisation enables to focus on the contribution of the EoL treatment of the biocomposite to the total environmental impacts of a European inhabitant.

\subsection{Goal and scope}

The aim of this paper is to evaluate the environmental impacts of the EoL of two biocomposites in France. As tonnages of biocomposite wastes are still low, specific waste management sectors are still not organized. Thus, the goal is to establish some requirements regarding biocomposite waste management, in order to minimize the ecological footprint of this part of the life cycle. Several EoL options have been considered: landfill, incineration with energy recovery, mechanical recycling and industrial composting for the PLA/Fl composite only. Anaerobic digestion was not studied as this technique is not widely used in France and more dedicated to agricultural wastes.

\subsection{Functional unit and system boundaries}

The functional unit chosen is: 'to manage 1 ton of biocomposite wastes'. The two biocomposites selected are: PP with wood flour (PP/WF) and PLA with flax fibers (PLA/Fl). The PP/WF composite contains $20 \%$ wt of wood flour and $5 \mathrm{wt} \%$ of PP grafted with maleic anhydride, used to enhance the compatibilisation between PP and WF. PLA/Fl composite contains $20 \mathrm{wt} \%$ of flax fibers, with $6 \mathrm{~mm}$ initial average length of fibres. These formulations are supposed to reflect biocomposites used or in development in the fields of construction and automotive respectively, $\mathrm{PP} / \mathrm{WF}$ composite is mainly used for decking application, while PLA/Fl can be found in the automotive sector. The system boundaries are presented in Fig. 1. The considered system begins at the waste treatment facilities and waste collection is not included. For each scenario, different processes are included: landfill, incineration and industrial composting do not required sorting facilities while a sorting step has been modeled for the mechanical recycling option. Avoided production processes, materials with mechanical recycling, compost with industrial composting and energy recovery through incineration, have been included by an extension of the system to evaluate the benefits of the recycling, the composting and the incineration. A step of transport between the waste treatment facility and the sites of recycling, composting, landfilling and incineration has been considered.

\subsection{Life cycle inventory and hypothesis}

Specific data from experiments were used when it was possible. Other data come from the Ecoinvent database 2.2, the Gabi@ software database or literature. Data representative of Europe systems were preferably used.

\subsubsection{Allocation}

To evaluate the benefits of recycling, composting and electricity production through incineration, the avoided burden approach was 


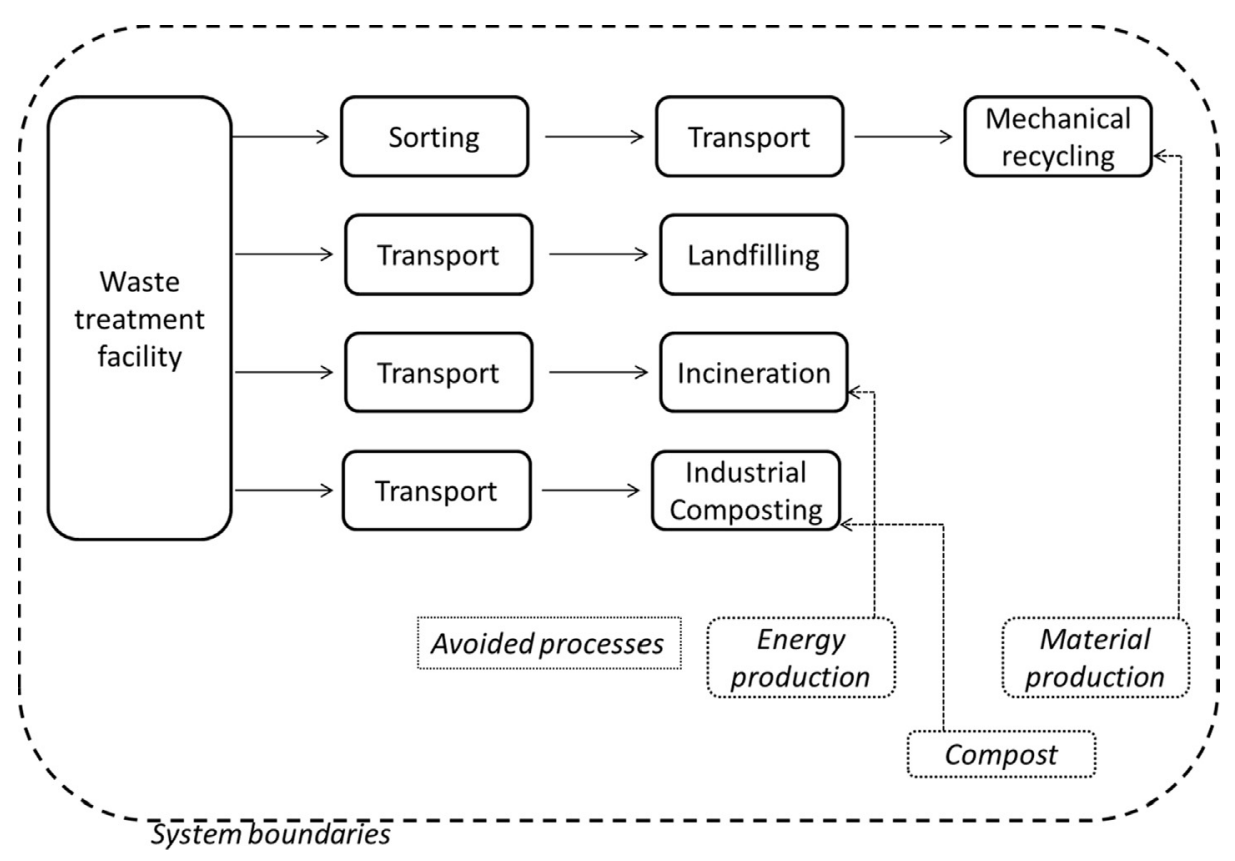

Fig. 1. Boundaries of the studied system.

chosen with an expansion of the system. This approach is the most used when the system studied concerns the EoL. The environmental impacts of the electricity and materials production (plastic, compost) were deduced to the system.

\subsubsection{Transport}

The location of each final treatment center was estimated at $100 \mathrm{~km}$ of the waste treatment facility. The trucks used were modeled with the process 16-32 t lorry, EURO4 from Ecoinvent.

\subsubsection{Landfill}

To model the landfill process, Ecoinvent data were used. PLA is not supposed to degrade in anaerobic conditions without a rise of temperature (Boyd, 2011; Kolstad et al., 2012), then it was estimated than $1 \mathrm{wt} \%$ will degrade during 100 years. Thus a process representative of a mixture of plastic was used to model the PLA landfilling, as also done in literature (Madival et al., 2009). No data were available for landfill of flax fibers and wood floor. They were both considered as untreated wood. Indeed, flax and wood are made of the same constituents (cellulose, hemicellulose, and lignin) but in different proportions.

\subsubsection{Incineration}

As for landfill, Ecoinvent processes were used to model the incineration step. For PLA, a plastic mixture process was adapted, the amount of $\mathrm{CO}_{2}$ released was adjusted with data from NatureWorks ("NatureWorks | Incineration," n.d.). Natural fibers were assimilated to untreated wood.

For the electricity production, it was assumed that incineration has a yield of $13 \%$, as an average value of European incinerators (Doka, 2007) and the French electricity mix was considered. Lower heating values (LHV) of biocomposites were assimilated to their total heat releases (THR), which were measured during combustion tests performed with a pyrolysis-combustion flow calorimeter (PCFC) (Sonnier et al., 2012). This method allows the characterization of an organic material flammability thanks to a pyrolysis chamber, where the material is totally degraded, coupled to a combustor chamber, where gases are burnt in an aerobic atmosphere and oxygen consumed. The analysis of the oxygen consumption leads to the flammability parameter calculations: heat release rate (HRR) or total heat release (THR) for instance. In this way, LHV values were estimated from the THR values at $32.2 \pm 1.3 \mathrm{MJ} / \mathrm{kg}$ for PP/ WF and $14.9 \pm 0.5 \mathrm{MJ} / \mathrm{kg}$ for PLA/fl.

\subsubsection{Recycling}

Several steps have been considered to model the recycling process of biocomposites (Fig. 2). They are similar to the recycling process of conventional plastics recycling. Thus, after shredding, biocomposites fragments were sorted thanks to an industrial online near-infrared (NIR) device developed by Pellenc ST (Pertuis, France). Sorting tests in collaboration with the Pellenc ST society enabled to estimate the sorting performances of the NIR sorting device with biocomposites samples. NIR sorting technologies lead to high purity. Some of the data used are presented in Table 1, laboratory measurements and specific test were performed to provide them. The separation efficiency represents the part of the material which is sorted; here the $15 \%$ lost are landfilled. For the washing step, $2 \mathrm{~m}^{3}$ of water were used for $1.25 \mathrm{t}$ of plastic wastes, and detergent soda in solution was added $\left(1 \mathrm{~kg} / \mathrm{m}^{3}\right.$ of water) (Shonfield, 2008).

Recycling leads to the production of a secondary raw material. In order to evaluate the credited impacts due to the production of the recycled biocomposites, production processes of PLA/Fl and $\mathrm{PP} / \mathrm{WF}$ were deduced to the system. Depending on the quality of the recycled material, it can replace entirely or partially a virgin material. For PP/WF composites, multiple reprocessing may not alter mechanical properties (Soccalingame et al., 2015a), it can even compensates degradation from UV ageing (Soccalingame et al., 2015b). For PLA, studies show that mechanical degradation occurs during reprocessing, and thus recycled PLA should be used mixed with virgin PLA (Brüster et al., 2016; Żenkiewicz et al., 2009). Moreover, real ageing, in function of the use of conditions of the materials, can alter significantly mechanical properties and visual appearance of the recycled biocomposites (Butylina et al., 2012; Fabiyi et al., 2008; Homkhiew et al., 2014). To simplify, in a first approach, recycled material was supposed to replace a virgin biocomposite, with the same mechanical properties, these parameter will then be studied in the sensitivity analysis. Wood floor pro- 


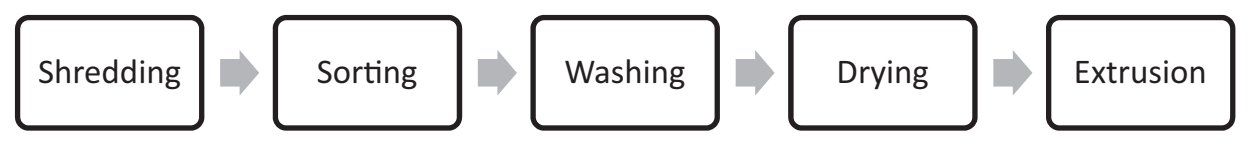

Fig. 2. Details of the recycling process.

Table 1

Internal data for the recycling steps.

\begin{tabular}{cll}
\hline & Data & References \\
\hline \multirow{2}{*}{ Shredding } & $154.8 \mathrm{MJ} /$ T shredded & Laboratory measurement \\
& $2 \mathrm{wt} \%$ of loss (landfilled) & \\
Sorting & Separation efficiency: $85 \%$ & Experiments in collaboration \\
& Power consumption : $11 \mathrm{~kW}$ & with Pellenc ST \\
& Throughput $3 \mathrm{t} / \mathrm{h}$ & \\
& Sorting refusal is landfilled & \\
Drying & $30 \mathrm{kWh} / \mathrm{t}$ & Laboratory measurement \\
\hline
\end{tabular}

duction was assimilated to timber pine production, the step of shredding of the wood has not been considered. Flax production data were extrapolated from Labouze et al., 2007, except terrestrial acidification and fossil depletion impacts which were not included in that study. Labouze et al.'s data considered flax culture and retting. PLA production data comes from Ecoinvent 2.2, which used data from Natureworks Company, the main producer of PLA. For all the bio-based materials recycled, the uptake of $\mathrm{CO}_{2}$ during the growth of the material was not taken into account. Indeed it was assumed that recycling biomaterials instead of producing materials from biomass could not lead to a reject of $\mathrm{CO}_{2}$ in the system (Gironi and Piemonte, 2011). For the PP production, data from Gabic software were used. A step of extrusion was also considered for the production of biocomposites; with a process data from the Gabic software database and electricity medium voltage French mix from Ecoinvent. The production of maleic anhydride, used as a compatibiliser for PP/WF was also considered (Ecoinvent). All materials that are lost during processes (shredding, sorting, and extrusion) were landfilled.

\subsubsection{Industrial composting}

The industrial composting scenario is only applied to the PLA/Fl which is biodegradable. A specific waste collect for biodegradable waste was assumed, thus sorting was not necessary before composting. A first step of shredding was considered, with the same data than for recycling process. The decomposition of PLA does not create nutriments (N-P-K), thus the composted material could not substitute fertilizer (Rossi et al., 2015). Data for modeling the PLA composting come from the work of Hermann et al., 2011, which reviewed several papers about composting of biodegradable materials. Input and global warming potential impact of the industrial composting of PLA are presented in Table 2. Emissions of carbon dioxide are dominant while methane and nitrous oxide emissions are low. Flax fibers were supposed to create a fibrous substrate in the compost which can substitute peat, thus impacts linked to the production of an equivalent quantity of peat were deduced to the system (ecoinvent data).

Table 2

Inventory of the composting process (Hermann et al., 2011).

\begin{tabular}{ll}
\hline Input & Impact (emission in $\mathrm{kg} \mathrm{CO}_{2}$ eq $/ \mathrm{kg}$ PLA) \\
\hline $1 \mathrm{~kg}$ of water/kg PLA & $\mathrm{CH}_{4}: 0.018$ \\
& $\mathrm{CO}_{2}: 1.47$ \\
& $\mathrm{~N}_{2} \mathrm{O}: 0.1 \mathrm{~kg}$ \\
\hline
\end{tabular}

\section{Results and discussion}

Environmental impacts of the EoL scenarios of PP/WF and PLA/Fl composites are presented on Fig. 3 and Fig. 5 respectively. For each scenario, three main steps are detailed: the impact of the treatment process, the impact of the transport step and the credit impact due to the recycling of the material (composite, peat) or the production of electricity. The net total impact is the sum of these three steps. European normalisations of the EoL treatments impacts are presented on Fig. 4 and Fig. 6, values are summarized in Table 5.

\subsection{PP/WF composites}

The recycling scenario presents the lowest net total impact scores, except for the freshwater eutrophication impact. In most of cases, credits coming from the production of the recycled biocomposites are higher or equivalent to the impacts of the recycling process. Indeed, the production of any polymer is at the origin of numerous impacts coming from all the energy and raw materials consumed during the entire process (fuel extraction, cracking, polymerization...) (PlasticsEurope, 2014). The freshwater eutrophication impact is mainly due to the electricity production in our study. Thus, incineration option leads to the lowest net impact score, thanks to the electricity production credit. Moreover, the recycling process has the highest eutrophication impact $(\approx 0.08 \mathrm{~kg}$ P.eq); this is mainly due to the production of electricity needed for the extrusion step.

Incineration option has the highest climate change impact $(\approx 2100 \mathrm{~kg} \mathrm{CO}$ eq). The process is responsible of important emissions of $\mathrm{CO}_{2}$, which are not compensated by the credit obtained from the production of electricity. Incineration scenario has also notable human toxicity and freshwater ecotoxicity impacts, with $145 \mathrm{~kg}$ 1,4-DB eq and $22 \mathrm{~kg}$ 1,4-DB eq respectively, due to the emissions of metallic elements to the water. For terrestrial acidification, photochemical oxidant formation, ozone depletion and fossil depletion, landfill and incineration have quiet similar total impacts, negligible compared to the credits obtained thanks to recycling.

Climate change and freshwater eutrophication impacts are minor for the landfill option. Nevertheless, landfill treatment causes important impacts on human toxicity and freshwater ecotoxicity, with $231 \mathrm{~kg}$ 1,4-DB eq and $39 \mathrm{~kg}$ 1,4-DB eq values respectively. Indeed, during landfill, leachates bring residual heavy metals from the catalyst of the polymer to groundwater.

The transport step impacts are negligible compared to the process or credit impacts for almost all the studied impacts, excepted for the photochemical oxidant formation and ozone depletion impacts.

Normalised scores reveal that freshwater eutrophication is the most contributing impact compared to the impact of a European (Fig. 3). Recycling is still the most ecological option, landfill and incineration are quiet similar for four of the studied impacts (HT, $\mathrm{OD}, \mathrm{PO}, \mathrm{TA})$, landfill has the highest score for freshwater ecotoxicity, and incineration is the most impacting option for CC impact.

\subsection{PLA/Fl composites}

For all the considered impacts, the recycling option presents the lowest net scores (Fig. 5). Indeed, credits coming from the recycling of PLA/Fl are more important than the impact of the recycling 


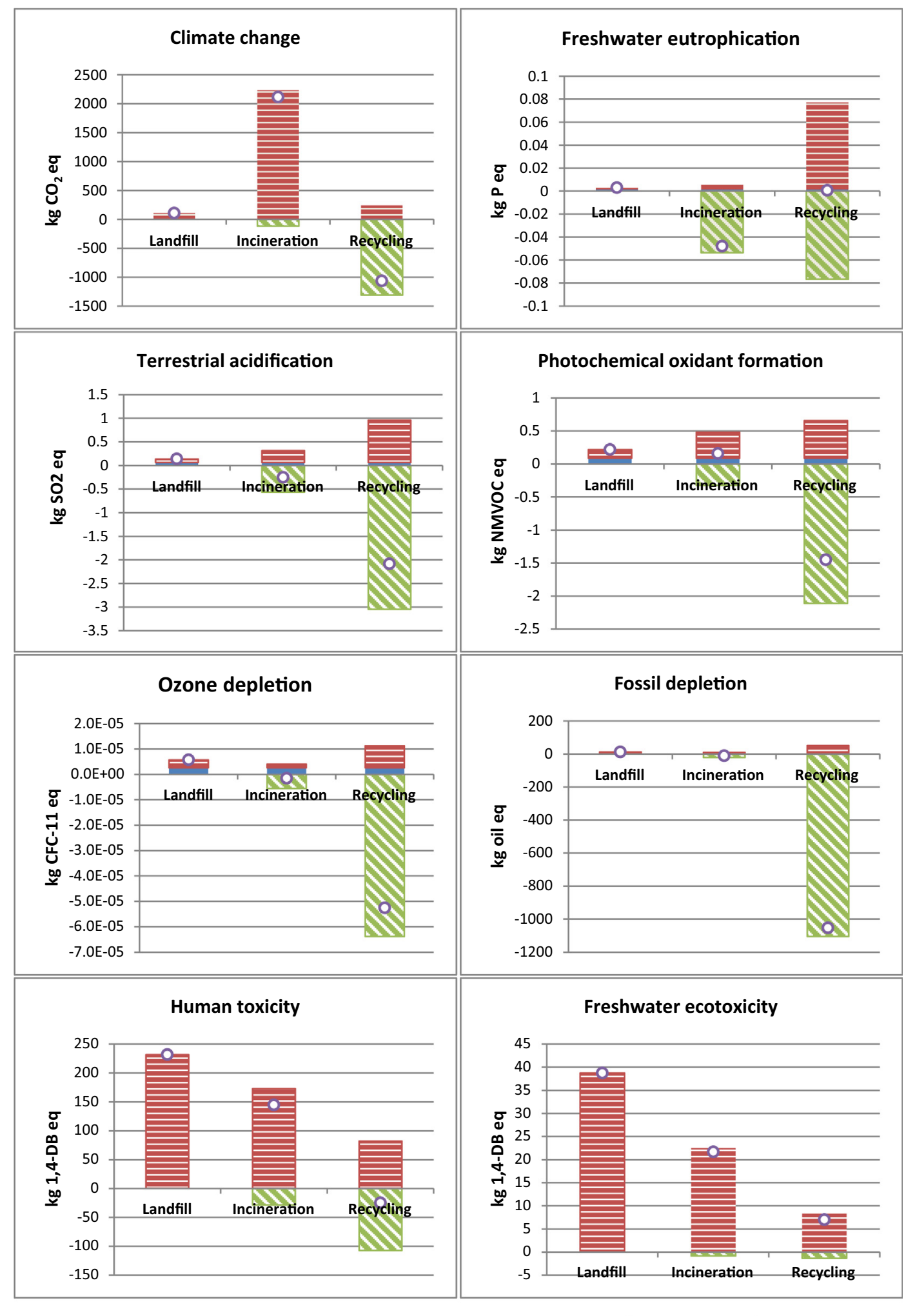

- Transport ETreatment processes $\mathbf{\Delta}$ Treatment credits $\circ$ Net Total

Fig. 3. Environmental impact scores for the EoL options of PP/WF composite.

process. Fertilizers used for the flax culture leads to important emissions of phosphate in water, during their production and in field with leaching phenomena (Labouze et al., 2007). Thus, the part of recycled flax fibres allows avoiding a notable part of freshwater eutrophication ( $\approx-0.5 \mathrm{~kg} \mathrm{P}$ eq). For the fossil depletion impact, the credit is mainly due to the energy consumption avoided during the production of the polymer, as PLA is a biosourced polymer. No data were found for the terrestrial acidification and the fossil depletion of the production of flax fibres, thus those impacts are underestimated for the recycling option of the PLA/Fl composite, with only the impact avoided by the production of $80 \mathrm{wt} \%$ of PLA. 


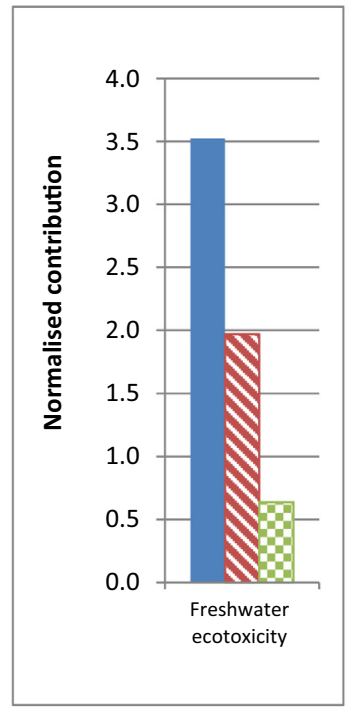

a)

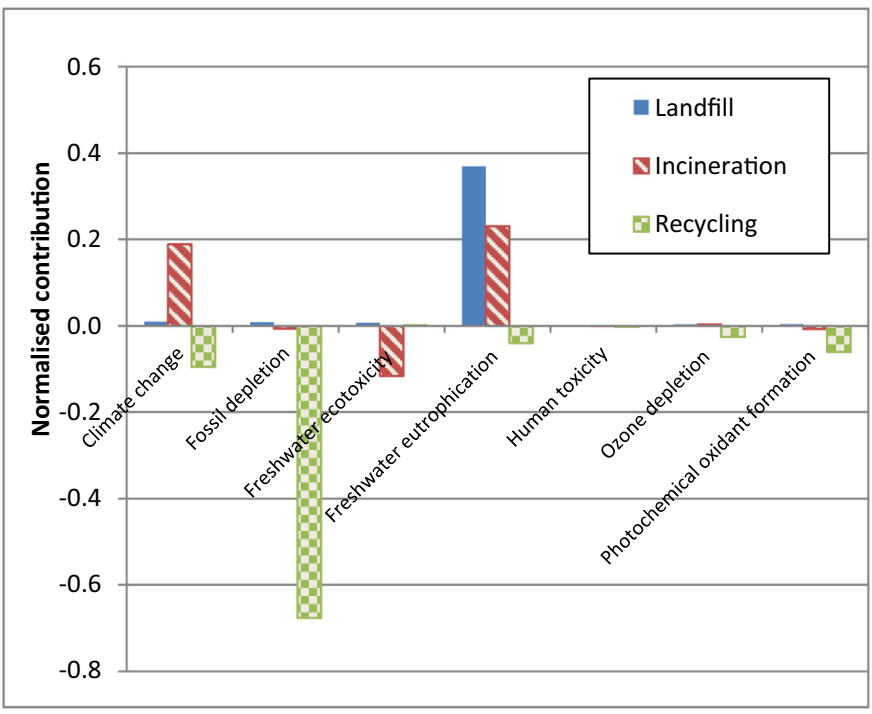

b)

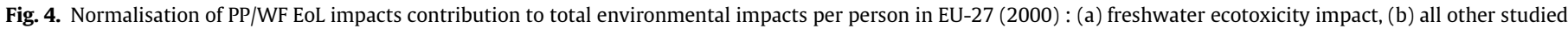
impacts.

For freshwater eutrophication, terrestrial acidification, photochemical oxidation, ozone depletion and fossil depletion, landfill, composting and incineration scenarios have similar net scores around zero.

Incineration and composting lead to important greenhouse gas emissions. Indeed, composting is at the origin of significant emissions of $\mathrm{CO}_{2}$, mainly emitted by the microorganisms destructing the matter (Hermann et al., 2011; Rossi et al.; 2015), while incineration emissions come from the process of combustion.

Landfill and incineration options have notable human toxicity and freshwater ecotoxicity impacts. Indeed, incineration is at the origin of emission of metallic elements into the water, while landfill leads to water pollution during lixiviation. It is worth noting that for the landfill and incineration modelling, PLA has been assimilated to a mixture of plastics by lack of data. Thus, impacts of human toxicity and freshwater ecotoxicity may be under or overestimated whether the nature of the catalyst used during PLA synthesis.

Except for the ozone depletion impact, the transport step has a negligible impact compared to the treatment processes and credits.

As for PP/WF, normalised scores show that the freshwater ecotoxicity impact is the most contributing at the European inhabitant scale. Recycling is still the best option, with credit for all the studied impacts. Except for freshwater ecotoxicity, human toxicity and climate change incineration, landfill and composting have low normalised scores.

\subsection{Sensitivity analysis}

Three parameters were tested through the sensitivity analysis, to simplify only the PP/WF model was selected.

The first parameter is the substitution ratio (s), which is defined as the ratio at which recycled plastic substitutes virgin plastic at equivalent properties (Astrup et al., 2009; Beigbeder et al., 2013; Rossi et al., 2015). Previous results were obtained assuming that recycled materials had the same properties than virgin biocomposites. In order to consider an eventual degradation of the mechanical properties for the recycled biocomposites, three substitution ratios were tested in the previous LCA model: $s=0.75, s=0.5$ and $\mathrm{s}=0.25$, with the model of the PP/WF EoL treatments (a substitution ratio of 0.75 means that $25 \%$ of virgin plastic is added to recy- cled plastic). For six of the studied impacts (CC, OD, FE, FD, PO and $\mathrm{HT}$ ), recycling is the less impacting option whatever the value of the substitution ratio is. For terrestrial acidification, below a substitution ration of 0.5 , incineration becomes the most interesting EoL scenario, as seen on Fig. 7. For freshwater eutrophication, incineration is the less impacting option, independently of the substitution ratio value.

The second parameter is the sorting efficiency. Previous results were obtained with a sorting efficiency of 0.85 as for conventional plastics. This parameter was not evaluated for biocomposites wastes on the sorting device. In-service ageing of materials can diminish this efficiency or the presence of natural fibers can lead to a better detection of biocomposites at the sorting step. Thus, the model was tested with two other sorting efficiencies: 0.7 and 0.9 . It can be observed that the general tendency is not modified; and that recycling is always the more efficient EoL option whatever the sorting efficiency selected.

Finally, the third parameter is the geographical location of the EoL treatment, and more especially the origin of the electricity production. Three countries were compared to France: Sweden, Germany and Great Britain, those countries were selected because of their different energetic mixes. Comparison of the net score impacts of the recycling and incineration options for the PP/WF material are presented in Tables 3 And 4 (values with an important deviation from the French result are in bold). For incineration, variations are notable, especially for Germany and Great Britain, which energetic mixes are more carbon dependent. For the recycling option, differences are less visible as impact of the process of recycling are compensated by the impact deduced by the production of the material.

For each countries, comparison between the different EoL options lead generally to the same results. The only exception is for the incineration option, in Great Britain, which did not lead to a credit impact for the photochemical oxidant formation impact.

Influence of the fibers percentage was not studied as loading ratios were already optimized to reach the best mechanical properties.

\subsection{Discussion}

For each biocomposite, recycling is obviously the preferable EoL scenario to avoid environmental impacts, thanks to the credits due 


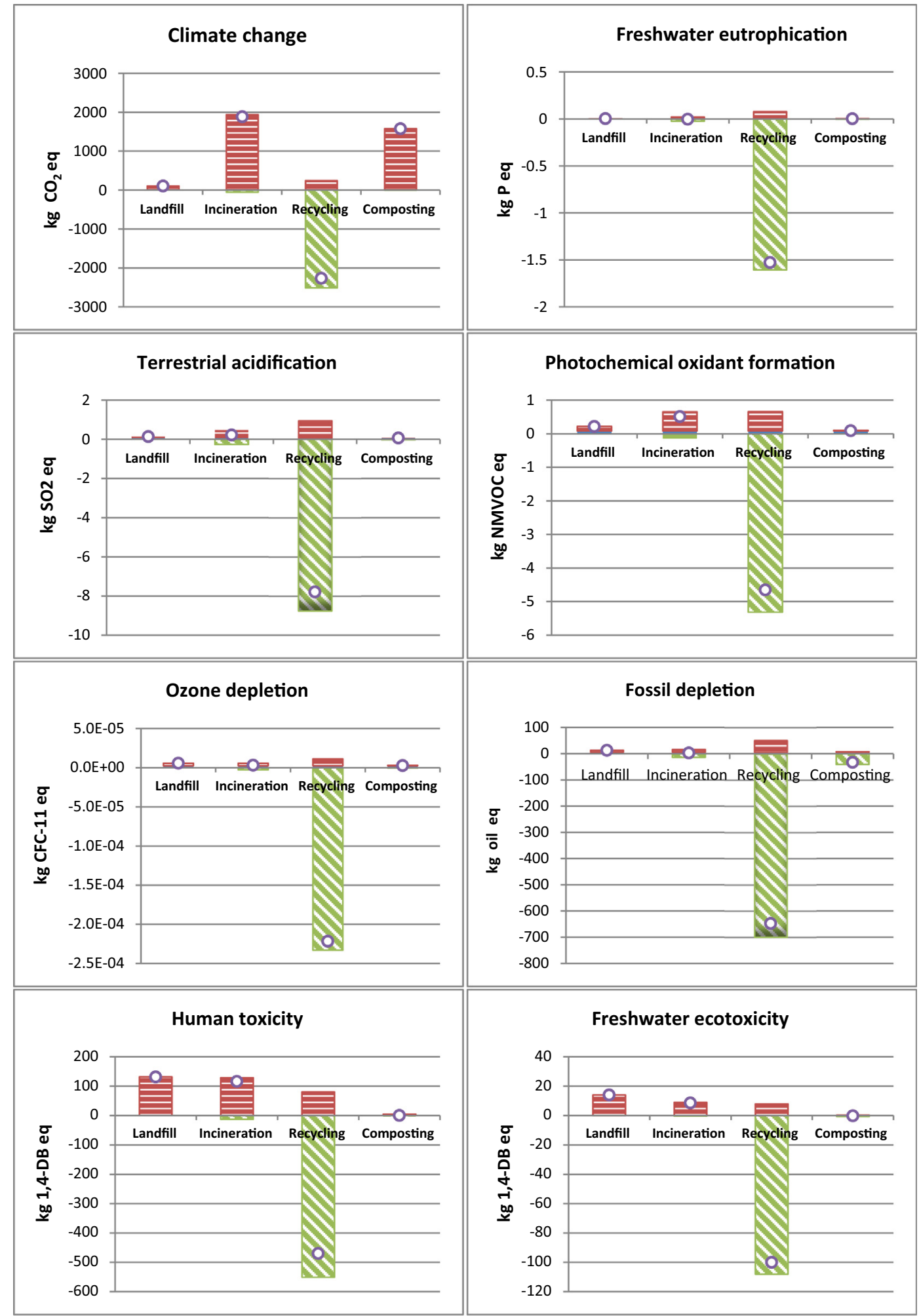

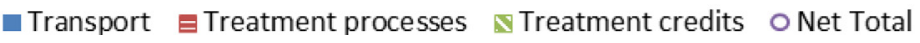

Fig. 5. Environmental impact scores for the EoL options of PLA/Fl composite.

to the material production avoided (Table 5). However, in practice, recycling, and more especially sorting of plastic wastes, can be difficult to perform (Badia and Ribes-Greus, 2016; Castro-Aguirre et al., 2016; Hopewell et al., 2009). Indeed, most of studies about recycling are done on material lab, and data are missing on real plastic waste recycling, submitted to various ageing parameters (food contamination, UV degradation, moisture, micro-organisms, heat, mechanical stress, chemicals). Moreover, a sufficient waste stream is necessary to establish a recycling sector and to lead to a recycled material economically competitive with virgin one. 


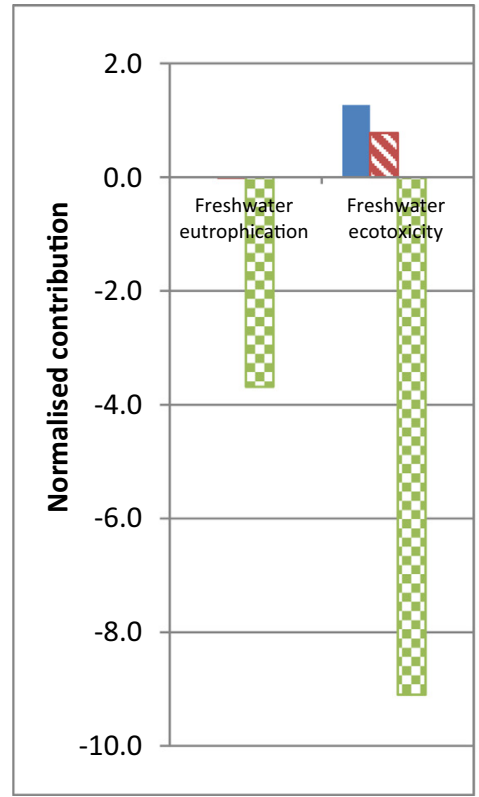

a)

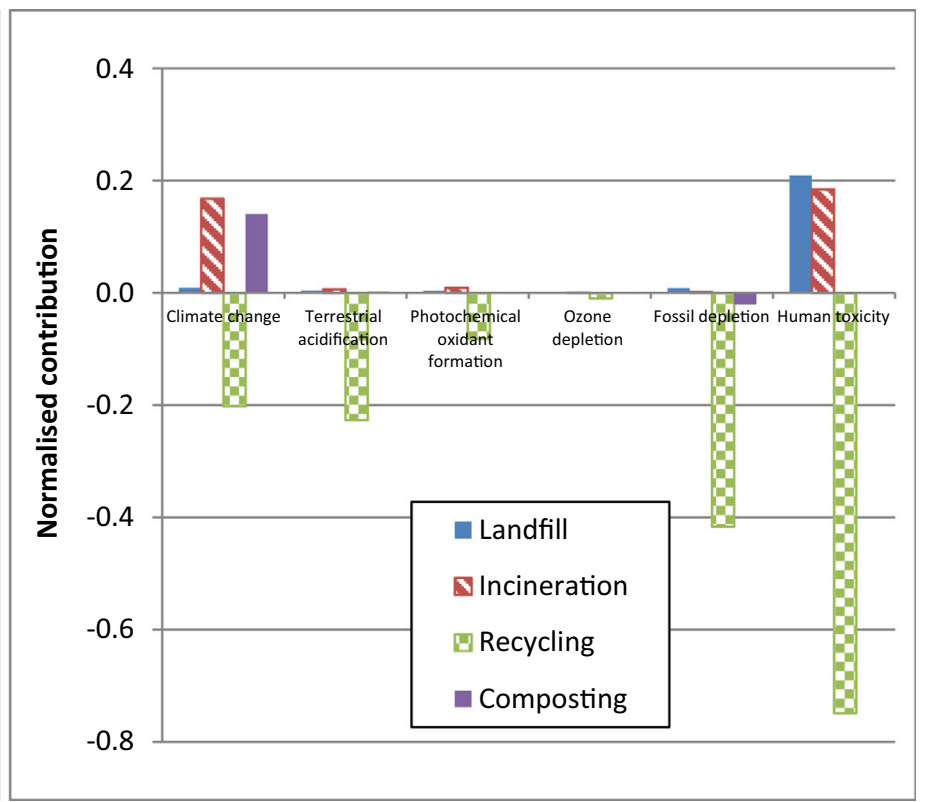

b)

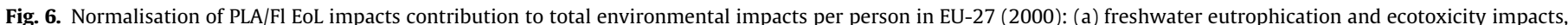
(b) all other studied impacts.

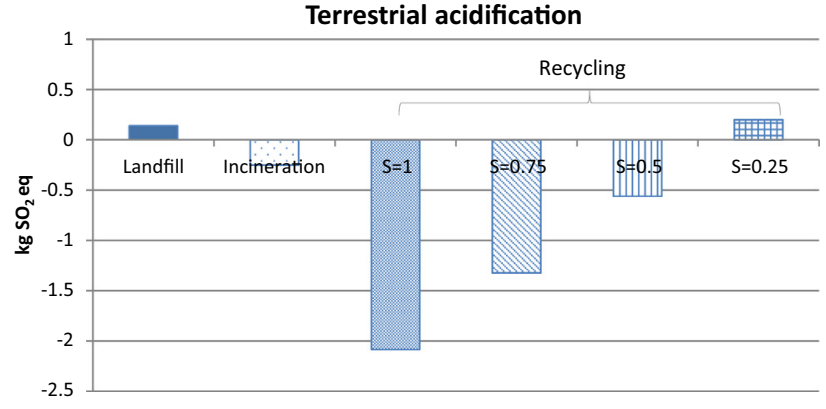

Fig. 7. Influence of the substitution ratio of $\mathrm{PP} / \mathrm{WF}$ recycling $\mathrm{S}$ on the terrestrial acidification impact compared to landfill and incineration scenarios.
Thus, if recycling cannot be performed, incineration seems to be the second preferable scenario for the PP/WF composites. Indeed, even if incineration has an important impact of climate change, landfill option has higher impacts on human toxicity and freshwater ecotoxicity. Moreover, normalisation results revealed that the freshwater ecotoxicity impact had the highest contribution at the European inhabitant level. Then, focus was made on freshwater ecotoxicity results for establishing the scenario hierarchy.

These results are in agreement with the European waste hierarchy and the majority of LCA dealing with EoL of plastics (Lazarevic et al., 2010; Rajendran et al., 2012; Wäger and Hischier, 2015). The presence of natural fibers in PP does not modify the trend obtained with plastic.

Table 3

Net score impacts of the incineration EoL option for the PP/WF in different European countries.

\begin{tabular}{|c|c|c|c|c|}
\hline & France & Germany & Sweden & Great Britain \\
\hline Climate change & $2.12 \mathrm{E}+03$ & $1.45 \mathrm{E}+03$ & $2.03 \mathrm{E}+03$ & $1.51 \mathrm{E}+03$ \\
\hline Fossil depletion & $-1.02 \mathrm{E}+01$ & $-1.96 \mathrm{E}+02$ & $-1.41 \mathrm{E}+01$ & $-2.06 \mathrm{E}+02$ \\
\hline Freshwater ecotoxicity & $2.17 \mathrm{E}+01$ & $1.28 \mathrm{E}+01$ & $2.18 \mathrm{E}+01$ & $2.01 \mathrm{E}+01$ \\
\hline Freshwater eutrophication & $-4.79 \mathrm{E}-02$ & $-9.32 E-01$ & $-4.14 \mathrm{E}-02$ & $-1.96 \mathrm{E}-01$ \\
\hline Human toxicity & $1.45 \mathrm{E}+02$ & $6.85 \mathrm{E}+01$ & $1.47 \mathrm{E}+02$ & $1.35 \mathrm{E}+02$ \\
\hline Ozone depletion & $-1.56 \mathrm{E}-06$ & $-2.83 E-05$ & $-1.04 E-05$ & $-1.35 E-05$ \\
\hline Photochemical oxidant formation & $1.59 \mathrm{E}-01$ & $-2.63 E-01$ & $1.95 \mathrm{E}-01$ & $-8.77 E-01$ \\
\hline Terrestrial acidification & $-2.51 \mathrm{E}-01$ & $-6.70 \mathrm{E}-01$ & $-5.76 \mathrm{E}-02$ & $-1.87 E+00$ \\
\hline
\end{tabular}

Table 4

Net score impacts of the recycling EoL option for the PP/WF in different European countries.

\begin{tabular}{|c|c|c|c|c|}
\hline & France & Germany & Sweden & Great Britain \\
\hline Climate change & $-1.06 \mathrm{E}+03$ & $-1.02 \mathrm{E}+03$ & $-1.06 \mathrm{E}+03$ & $-1.03 E+03$ \\
\hline Fossil depletion & $-1.05 E+03$ & $-1.03 E+03$ & $-1.05 \mathrm{E}+03$ & $-1.04 \mathrm{E}+03$ \\
\hline Freshwater ecotoxicity & $7.01 \mathrm{E}+00$ & $3.42 \mathrm{E}+00$ & $2.87 \mathrm{E}+00$ & $2.97 \mathrm{E}+00$ \\
\hline Freshwater eutrophication & $7.04 \mathrm{E}-04$ & $5.56 E-02$ & $2.07 \mathrm{E}-04$ & $9.84 \mathrm{E}-03$ \\
\hline Human toxicity & $-2.48 \mathrm{E}+01$ & $-3.68 \mathrm{E}+01$ & $-4.17 \mathrm{E}+01$ & $-4.10 \mathrm{E}+01$ \\
\hline Ozone depletion & $-5.26 \mathrm{E}-05$ & $-5.09 \mathrm{E}-05$ & $-5.21 \mathrm{E}-05$ & $-5.18 \mathrm{E}-05$ \\
\hline Photochemical oxidant formation & $-1.45 \mathrm{E}+00$ & $-1.42 \mathrm{E}+00$ & $-1.45 \mathrm{E}+00$ & $-1.39 \mathrm{E}+00$ \\
\hline Terrestrial acidification & $-2.08 \mathrm{E}+00$ & $-2.06 \mathrm{E}+00$ & $-2.09 \mathrm{E}+00$ & $-1.98 \mathrm{E}+00$ \\
\hline
\end{tabular}


Table 5

Normalisation scores of the four studied options for PP/WF and PLA/Fl composites.

\begin{tabular}{|c|c|c|c|c|c|c|c|c|}
\hline & $\begin{array}{l}\text { Climate } \\
\text { change }\end{array}$ & $\begin{array}{l}\text { Fossil } \\
\text { depletion }\end{array}$ & $\begin{array}{l}\text { Freshwater } \\
\text { ecotoxicity }\end{array}$ & $\begin{array}{l}\text { Freshwater } \\
\text { eutrophication }\end{array}$ & $\begin{array}{l}\text { Human } \\
\text { toxicity }\end{array}$ & $\begin{array}{l}\text { Ozone } \\
\text { depletion }\end{array}$ & $\begin{array}{l}\text { Photochemical } \\
\text { oxidant formation }\end{array}$ & $\begin{array}{l}\text { Terrestrial } \\
\text { acidification }\end{array}$ \\
\hline \multicolumn{9}{|l|}{ Landfill } \\
\hline $\mathrm{PP} / \mathrm{WF}$ & $9.6 \mathrm{E}-03$ & $8.5 \mathrm{E}-03$ & $3.5 \mathrm{E}+00$ & $7.2 \mathrm{E}-03$ & $3.7 \mathrm{E}-01$ & $2.6 \mathrm{E}-04$ & $3.8 \mathrm{E}-03$ & $4.1 \mathrm{E}-03$ \\
\hline $\mathrm{PLA} / \mathrm{Fl}$ & $9.3 \mathrm{E}-03$ & $7.1 \mathrm{E}-03$ & $4.1 \mathrm{E}-03$ & $3.8 \mathrm{E}-03$ & $2.6 \mathrm{E}-04$ & $8.5 \mathrm{E}-03$ & $2.1 \mathrm{E}-01$ & $1.3 \mathrm{E}+00$ \\
\hline \multicolumn{9}{|l|}{ Incineration } \\
\hline $\mathrm{PP} / \mathrm{WF}$ & $1.9 \mathrm{E}-01$ & $-6.6 \mathrm{E}-03$ & $2.0 \mathrm{E}+00$ & $-1.2 \mathrm{E}-01$ & $2.3 \mathrm{E}-01$ & $-7.1 \mathrm{E}-05$ & $2.8 \mathrm{E}-03$ & $-7.3 \mathrm{E}-03$ \\
\hline PLA/Fl & $1.7 \mathrm{E}-01$ & $-7.7 \mathrm{E}-03$ & $6.4 \mathrm{E}-03$ & $9.0 \mathrm{E}-03$ & $1.4 \mathrm{E}-04$ & $2.1 \mathrm{E}-03$ & $1.8 \mathrm{E}-01$ & $7.7 \mathrm{E}-01$ \\
\hline \multicolumn{9}{|l|}{ Recycling } \\
\hline $\mathrm{PP} / \mathrm{WF}$ & $-9.5 \mathrm{E}-02$ & $-6.8 \mathrm{E}-01$ & $6.4 \mathrm{E}-01$ & $1.7 \mathrm{E}-03$ & $-4.0 \mathrm{E}-02$ & $-2.4 \mathrm{E}-03$ & $-2.6 \mathrm{E}-02$ & $-6.1 \mathrm{E}-02$ \\
\hline PLA/Fl & $-2.0 \mathrm{E}-01$ & $-3.7 \mathrm{E}+00$ & $-2.3 \mathrm{E}-01$ & $-8.2 \mathrm{E}-02$ & $-1.0 \mathrm{E}-02$ & $-4.2 \mathrm{E}-01$ & $-7.5 \mathrm{E}-01$ & $-9.1 \mathrm{E}+00$ \\
\hline \multicolumn{9}{|l|}{ Composting } \\
\hline $\mathrm{PLA} / \mathrm{Fl}$ & $1.4 \mathrm{E}-01$ & $4.6 \mathrm{E}-03$ & $2.1 \mathrm{E}-03$ & $1.6 \mathrm{E}-03$ & $1.2 \mathrm{E}-04$ & $-2.1 \mathrm{E}-02$ & $5.0 \mathrm{E}-04$ & $-1.9 \mathrm{E}-02$ \\
\hline
\end{tabular}

For the PLA/Fl composites, composting is the second preferable EoL scenario. Indeed, composting option has lower freshwater ecotoxicity and human toxicity impacts than incineration and landfill. In addition, as for the PP/WF composite, the European normalisation also revealed that the freshwater ecotoxicity impact had the highest contribution at the European scale. If composting cannot be performed then incineration should be preferred than landfill as freshwater ecotoxicity and human toxicity impacts are lower.

\section{Conclusion}

LCA was applied to the treatment of two emergent biocomposite wastes in order to predict best environmental practices for EoL management. These biocomposites are polypropylene reinforced with wood flour, commonly used as decking in building sector and polylactic acid reinforced with flax fibers, considered as an emergent biocomposite in indoor automotive applications.

For both biocomposites, recycling EoL scenario presents the lowest environmental impacts, followed by industrial composting for PLA/Fl composite, and incineration for PP/WP. Energy recovery and landfill are the less interesting EoL scenarios considering the environmental impacts. In most cases, benefits from the production of recycled materials or energy compensate the impacts of waste treatment processes. Except for ozone depletion, benefits from recycling were most important for the PLA/Fl composites than for the PP/WF. Even if EoL treatment impacts are dependent on the geographical location, the place did not modify the main result: recycling is the best environmental friendly solution.

Nevertheless, for PLA/Fl biocomposites, data are still missing. Specific data about sorting and energy recovery were provided here with laboratory experiments. Models should be completed in the future when new data will be available.

Results obtained for both biocomposites are in agreement with the European waste hierarchy. These LCA results can help waste management stakeholders to make decisions for these emerging wastes, but also material engineers in the selection of materials during product developments.

\section{Acknowledgment}

Authors thank the ADEME (France) for financial support (convention no. 1101C0066, acronym ENOLIBIO "ENd Of LIfe of BIOcomposites").

\section{References}

Astrup, T., Fruergaard, T., Christensen, T.H., 2009. Recycling of plastic: accounting of greenhouse gases and global warming contributions. Waste Manage. Res. 27, 763-772. https://doi.org/10.1177/0734242X09345868.

Badia, J.D., Ribes-Greus, A., 2016. Mechanical recycling of polylactide wastes, upgrading trends and combination of valorisation techniques: a review. Manuscr. Prep. 84, 22-39. https://doi.org/10.1016/j.eurpolymj.2016.09.005.
Bayerl, T., Geith, M., Somashekar, A.A., Bhattacharyya, D., 2014. Influence of fibre architecture on the biodegradability of FLAX/PLA composites. Int. Biodeterior. Biodegrad. 96, 18-25. https://doi.org/10.1016/J.IBIOD.2014.08.005.

Beigbeder, J., Perrin, D., Mascaro, J.-F., Lopez-Cuesta, J.-M., 2013. Study of the physico-chemical properties of recycled polymers from waste electrical and electronic equipment (WEEE) sorted by high resolution near infrared devices. Resour. Conserv. Recycl. 78. https://doi.org/10.1016/j.resconrec.2013.07.006.

Bensadoun, F., Vanderfeesten, B., Verpoest, I., Van Vuure, A.W., Van Acker, K., 2016. Environmental impact assessment of end of life options for flax-MAPP composites. Ind. Crops Prod. 94, 327-341. https://doi.org/10.1016/J. INDCROP.2016.09.006.

Bhattacharjee, S., Bajwa, D.S., 2018. Degradation in the mechanical and thermomechanical properties of natural fiber filled polymer composites due to recycling. Constr. Build. Mater. 172, 1-9. https://doi.org/10.1016/J CONBUILDMAT.2018.03.010.

Boyd, S.B., 2011. Bio-Based versus conventional plastics for electronics housings: LCA Literature Review Bio-based versus conventional plastics for electronics housings: LCA literature review (White Paper). Sustain. Consortium, Electron. 15. doi:White Paper \#101.

Brüster, B., Addiego, F., Hassouna, F., Ruch, D., Raquez, J.-M., Dubois, P., 2016 Thermo-mechanical degradation of plasticized poly(lactide) after multiple reprocessing to simulate recycling: multi-scale analysis and underlying mechanisms. Polym. Degrad. Stab. 131, 132-144. https://doi.org/10.1016/J. POLYMDEGRADSTAB.2016.07.017.

Butylina, S., Hyvärinen, M., Kärki, T., 2012. A study of surface changes of woodpolypropylene composites as the result of exterior weathering. Polym. Degrad. Stab. 97, 337-345. https://doi.org/10.1016/j.polymdegradstab.2011.12.014.

Castro-Aguirre, E., Iñiguez-Franco, F., Samsudin, H., Fang, X., Auras, R., 2016. Poly (lactic acid)-Mass production, processing, industrial applications, and end of life. Adv. Drug Deliv. Rev. 107, 333-366. https://doi.org/10.1016/j. addr.2016.03.010.

Chen, H.-L., Porter, R.S., 1994. Composite of polyethylene and kenaf, a natura cellulose fiber. J. Appl. Polym. Sci. 54, 1781-1783. https://doi.org/10.1002 app.1994.070541121.

Corbière-Nicollier, T., Gfeller Laban, B., Lundquist, L., Leterrier, Y., Manson, J.A. Jolliet, O., 2001. Life cycle assessment of biofibres replacing glass fibres as reinforcement in plastics. Resour. Conserv. Recycl. 33, 267-287.

Doka, G., 2007. Life Cycle Inventories of Waste Treatment Services. Ecoinvent report No. 13. Swiss Cent. Life Cycle Invent. Dübend.

Dornburg, V., Lewandowski, I., Patel, M., 2003. Comparing the land requirements, energy savings, and greenhouse gas emissions reduction of biobased polymers and bioenergy. J. Ind. 7, 93-116. https://doi.org/10.1162/ 108819803323059424.

Ecoinvent Life Cycle Impact assessment database, 2006

European Bioplastics, 2013. Bioplastics - facts and figures 6. doi:10.1089/ ind.2012.1516

Commission, European, 2008. Directive 2008/98/EC of the European Parliament and of the Council of 19 November 2008 on waste and repealing certain directives. Off. J. Eur. Union L13, 3-30. doi:2008/98/EC.; 32008L0098.

Fabiyi, J.S., McDonald, A.G., Wolcott, M.P., Griffiths, P.R., 2008. Wood plastic composites weathering: visual appearance and chemical changes. Polym. Degrad. Stab. 93, 1405-1414. https://doi.org/10.1016/j. polymdegradstab.2008.05.024.

Frischknecht, R., 2010. LCI modelling approaches applied on recycling of materials in view of environmental sustainability, risk perception and eco-efficiency. Int J. Life Cycle Assess. 15, 666-671. https://doi.org/10.1007/s11367-010-0201-6.

Gironi, F., Piemonte, V., 2011. Life cycle assessment of polylactic acid and polyethylene terephthalate bottles for drinking water. Environ. Prog. Sustain. Energy 30, 459-468. https://doi.org/10.1002/ep.10490.

Goedkoop, M., Heijungs, R., Huijbregts, M., Schryver, A. De, Struijs, J., Zelm, R. Van, 2009. ReCiPe 2008 .

González-Sánchez, C., Martínez-Aguirre, A., Pérez-García, B. Acosta, J., FonsecaValero, C., De La Orden, M.U., Sánchez, C., Martínez Urreaga, J., 2016 Enhancement of mechanical properties of waste-sourced biocomposites through peroxide induced crosslinking. Compos. Part A Appl. Sci. Manuf. 80, 285-291. https://doi.org/10.1016/j.compositesa.2015.10.032. 
Hermann, B.G., Debeer, L., De Wilde, B., Blok, K., Patel, M.K., 2011. To compost or not to compost: carbon and energy footprints of biodegradable materials' waste treatment. Polym. Degrad. Stab. 96, 1159-1171. https://doi.org/10.1016/j. polymdegradstab.2010.12.026.

Homkhiew, C., Ratanawilai, T., Thongruang, W., 2014. Effects of natural weathering on the properties of recycled polypropylene composites reinforced with rubberwood flour. Ind. Crops Prod. 56, 52-59. https://doi.org/10.1016/j. indcrop.2014.02.034.

Hopewell, J., Dvorak, R., Kosior, E., 2009. Plastics recycling: challenges and opportunities. Philos. Trans. R. Soc. Lond. B. Biol. Sci. 364, 2115-2126. https:// doi.org/10.1098/rstb.2008.0311.

Jenseit, W., Stahl, H., Wollny, V., 2003. Recovery Options for Plastic Parts from Endof-Life Vehicles: an Eco-Efficiency Assessment. Öko-Institut e.V.

Joseph, K., Thomas, S., Pavithran, C., 1996. Effect of chemical treatment on the tensile properties of short sisal fibre-reinforced polyethylene composites. Polymer (Guildf) 37, 5139-5149. https://doi.org/10.1016/0032-3861(96) 00144-9.

Joshi, S.V., Drzal, L.T., Mohanty, A.K., Arora, S., 2004. Are natural fiber composites environmentally superior to glass fiber reinforced composites? Compos. Part A Appl. Sci. Manuf. 35, 371-376. https://doi.org/10.1016/ j.compositesa.2003.09.016.

Koffler, C., Finkbeiner, M., 2018. Are we still keeping it "real"? Proposing a revised paradigm for recycling credits in attributional life cycle assessment. Int. J. Life Cycle Assess. 23, 181-190. https://doi.org/10.1007/s11367-017-1404-X.

Kolstad, J.J., Vink, E.T.H., De Wilde, B., Debeer, L., 2012. Assessment of anaerobic degradation of Ingeo ${ }^{\mathrm{TM}}$ polylactides under accelerated landfill conditions. Polym. Degrad. Stab. 97, 1131-1141. https://doi.org/10.1016/j. polymdegradstab.2012.04.003.

La Rosa, A.D., Cozzo, G., Latteri, A., Recca, A., Björklund, A., Parrinello, E., Cicala, G. 2013. Life cycle assessment of a novel hybrid glass-hemp/thermoset composite. J. Clean. Prod. 44, 69-76. https://doi.org/10.1016/j.jclepro.2012.11.038.

Labouze, E., Le Guern, Y., Petiot, C., 2007. Analyse du Cycle de Vie comparée d'une chemise en lin et d'une chemise en coton. Bio Intell. Serv. 33, 1-117.

Lazarevic, D., Aoustin, E., Buclet, N., Brandt, N., 2010. Plastic waste management in the context of a European recycling society: comparing results and uncertainties in a life cycle perspective. Resour. Conserv. Recycl. 55, 246-259. https://doi.org/10.1016/j.resconrec.2010.09.014.

Le Duigou, A., Pillin, I., Bourmaud, A., Davies, P., Baley, C., 2008. Effect of recycling on mechanical behaviour of biocompostable flax/poly(l-lactide) composites. Compos. Part A Appl. Sci. Manuf. 39, 1471-1478. https://doi.org/10.1016/ j.compositesa.2008.05.008.

Madival, S., Auras, R., Singh, S.P., Narayan, R., 2009. Assessment of the environmental profile of PLA, PET and PS clamshell containers using LCA methodology. J. Clean. Prod. 17, 1183-1194. https://doi.org/10.1016/j. jclepro.2009.03.015.

NatureWorks | Incineration [WWW Document], n.d. URL https:// www.natureworksllc.com/What-is-Ingeo/Where-it-Goes/Incineration (accessed 9.18.18)

Othman, M., Nor Azowa, I., Ruzaidi, C.M., Mohd Nazarudin, Z., Halim, Z., 2012. Biodegradability analysis of KBF reinforced poly(lactic Acid) biocomposites. Adv. Mater. Res. 576, 434-437. https://doi.org/10.4028/www.scientific.net/ AMR.576.434.

Pennington, D.W., Potting, J., Finnveden, G., Lindeijer, E., Jolliet, O., Rydberg, T., Rebitzer, G., 2004. Life cycle assessment Part 2: current impact assessment practice. Environ. Int. 30, 721-739. https://doi.org/10.1016/j. envint.2003.12.009.

PlasticsEurope, 2014. Polypropylene (PP), Eco-profiles and Environmental Product Declarations of the European Plastics Manufacturers.

Pradhan, R., Misra, M., Erickson, L., Mohanty, A., 2010. Compostability and biodegradation study of PLA-wheat straw and PLA-soy straw based green composites in simulated composting bioreactor. Bioresour. Technol. 101, 84898491. https://doi.org/10.1016/J.BIORTECH.2010.06.053.
Puech, L., Ramakrishnan, K.R., Le Moigne, N., Corn, S., Slangen, P.R., Duc, A. Le, Boudhani, H., Bergeret, A., 2018. Investigating the impact behaviour of short hemp fibres reinforced polypropylene biocomposites through high speed imaging and finite element modelling. Compos. Part A Appl. Sci. Manuf. 109, 428-439. https://doi.org/10.1016/j.compositesa.2018.03.013.

Rajendran, S., Scelsi, L., Hodzic, A., Soutis, C., Al-Maadeed, M.A., 2012. Environmental impact assessment of composites containing recycled plastics. Resour. Conserv. Recycl. 60, 131-139. https://doi.org/10.1016/j.resconrec.2011.11.006.

Rebitzer, G., Ekvall, T., Frischknecht, R., Hunkeler, D., Norris, G., Rydberg, T., Schmidt W.-P., Suh, S., Weidema, B.P., Pennington, D.W., 2004. Life cycle assessment. Environ. Int. 30, 701-720. https://doi.org/10.1016/j.envint.2003.11.005.

Rigamonti, L., Grosso, M., Møller, J., Martinez Sanchez, V., Magnani, S., Christensen, T.H., 2014. Environmental evaluation of plastic waste management scenarios. Resour. Conserv. Recycl. 85, 42-53. https://doi.org/10.1016/j.resconrec.2013.12.012.

Ross, S., Evans, D., 2003. The environmental effect of reusing and recycling a plasticbased packaging system. J. Clean. Prod. 11, 561-571. https://doi.org/10.1016/ S0959-6526(02)00089-6.

Rossi, V., Cleeve-Edwards, N., Lundquist, L., Schenker, U., Dubois, C., Humbert, S., Jolliet, O., 2015. Life cycle assessment of end-of-life options for two biodegradable packaging materials: sound application of the European waste hierarchy. J. Clean. Prod. 86, 132-145. https://doi.org/10.1016/j. jclepro.2014.08.049.

Sarasini, F., Fiore, V., 2018. A systematic literature review on less common natural fibres and their biocomposites. J. Clean. Prod. 195, 240-267. https://doi.org/ 10.1016/j.jclepro.2018.05.197.

Schmidt, W.-P., Beyer, H.-M., 1998. Life cycle study on a natural fibre reinforced component. SAE Technical Paper 982195, 2095-2102. https://doi.org/10.4271/ 982195.

Shen, L., Worrell, E., Patel, M., 2010. Present and future development in plastics from biomass. Biofuels. Bioprod. Biorefining 4, 25-40. https://doi.org/10.1002/bbb.

Shonfield, P., 2008. LCA of Management Options for Mixed Waste Plastics, Waste resource action programme WRAP. doi:1-81105-397-0

Soccalingame, L., Bourmaud, A., Perrin, D., Bénézet, J.-C., Bergeret, A., 2015a. Reprocessing of wood flour reinforced polypropylene composites: impact of particle size and coupling agent on composite and particle properties. Polym. Degrad. Stab. 113, 72-85. https://doi.org/10.1016/j.polymdegradstab.2015. 01.020 .

Soccalingame, L., Perrin, D., Bénézet, J.-C., Mani, S., Coiffier, F., Richaud, E., Bergeret, A., 2015b. Reprocessing of artificial UV-weathered wood flour reinforced polypropylene composites. Polym. Degrad. Stab. 120, 313-327. https://doi. org/10.1016/j.polymdegradstab.2015.07.013.

Sommerhuber, P.F., Wenker, J.L., Rüter, S., Krause, A., 2017. Life cycle assessment of wood-plastic composites: analysing alternative materials and identifying an environmental sound end-of-life option. Resour. Conserv. Recycl. 117, 235-248. https://doi.org/10.1016/j.resconrec.2016.10.012.

Sonnier, R., Vahabi, H., Ferry, L., Lopez-Cuesta, J.-M., 2012. Pyrolysis-combustion flow calorimetry: a powerful tool to evaluate the flame retardancy of polymers. In: Fire and Polymers VI: New Advances in Flame Retardant Chemistry and Science, pp. 361-390. https://doi.org/10.1021/bk-2012-1118.ch024.

Srebrenkoska, V., Gaceva, G.B., Avella, M., Errico, M.E., Gentile, G., 2008. Recycling of polypropylene-based eco-composites. Polym. Int. 57, 1252-1257. https://doi. org/10.1002/pi.2470.

Wäger, P.A., Hischier, R., 2015. Life cycle assessment of post-consumer plastics production from waste electrical and electronic equipment (WEEE) treatment residues in a Central European plastics recycling plant. Sci. Total Environ. 529, 158-167. https://doi.org/10.1016/j.scitotenv.2015.05.043.

Żenkiewicz, M., Richert, J., Rytlewski, P., Moraczewski, K., Stepczyńska, M., Karasiewicz, T., 2009. Characterisation of multi-extruded poly(lactic acid). Polym. Test. 28, 412-418. https://doi.org/10.1016/J. POLYMERTESTING.2009.01.012.

Zini, E., Scandola, M., 2011. Green composites: an overview. Polym. Compos. 32 1905-1915. https://doi.org/10.1002/pc.21224. 